\title{
Enterprise Architecture Definition Framework for IT Service Providers
}

\author{
Shankar Kambhampaty and Satish Chandra \\ Technology Architecture Group - CHB, \\ Satyam Computer Services Limited, \\ C5, TSR Towers, Raj Bhavan Road, \\ Somajiguda, Hyderabad - 500 082, India \\ \{Shankar_Kambhampaty, Satish_Chandra\} @satyam.com
}

\begin{abstract}
As Enterprises evolve, they invariably end up with heterogeneous IT systems. The software applications for the IT systems would have been deployed on multiple platforms and built using varied programming languages or packaged software. Customers require approaches to plan enterprise wide strategies that lead to scenarios of well integrated IT systems within their organizations. Suitable integration strategies have to be adopted to ensure that the systems which are currently available are wellintegrated as well as enable future systems to be easily brought into their fold through seamless integration.
\end{abstract}

In order to address customer requirements for developing enterprise architectures and also to develop strategies to maintain them, customized approaches have been adopted. This resulted in the development of an Enterprise Architecture Definition Framework that IT Service providers can apply in consulting assignments. The paper presents the best practices for enterprise architecting and integration. Two case studies have also been included in the paper to illustrate the approach, one based on a native integration framework and the other based on Enterprise-Wide Service Oriented Architecture.

\section{Introduction}

The Information Technology services department of a typical organization has moved from playing the role of a supporting partner to that of a strategic partner.

Please use the following format when citing this chapter: 
From the scenario of having an Electronic Data Processing Officer/Manager who would generate the required reports for the user departments we have reached a stage where large enterprises have Chief Information Officers and IT Directors to drive the IT strategies of their enterprises. Information Technology (IT) has become the backbone of almost every business enterprise. Consulting organizations are being employed to develop and setup the required applications/systems on a large scale. Hence, there is a need to provide detail to the various stake holders at a level of abstraction that they are comfortable with, when communicating with others.

Further, large enterprises would have already invested a considerable amount of resources while evolving to the current state of IT implementation. Consequently, there is a need to integrate the heterogeneous applications/systems and also to have a clear path to integrate the applications/systems that the enterprise would acquire in future.

Thus, there is a need for effective communication of the requirements of various stake holders within an enterprise and also while communicating with an outsourcing partner, when the enterprise engages an IT Service Provider. The communication would be highly effective through an Enterprise Architecture. This paper discusses an Enterprise Architecture Definition Framework for IT Service Providers.

The paper is based on customer engagements that involved recommending and providing Enterprise Architecture based solutions. In this paper, large-scale business applications built on distributed systems are referred to as "Enterprise Applications". Two customer case studies have been discussed in the paper.

The rest of this paper is organized as follows. Section 2 discusses the concept of Enterprise Architecture (EA) and its current stage of adoption. Section 3 discusses the Enterprise Architecture Definition Framework for IT Service Providers. Section 4 describes the generic approach to Enterprise Architecting and instantiates it with two case studies, one based on a native integration framework and the other based on Enterprise-Wide Service Oriented Architecture. Section 5 concludes the paper.

\section{Enterprise Architecture - The concept and its current stage of adoption}

Enterprise Architecture involves the integration of processes and applications across an enterprise and is a collection of architectures. It involves the gathering and documenting of AS-IS/Current state and TO-BE/Future state requirements of 
various stake holders from different dimensions, such as business, information, applications, infrastructure and security. In case the enterprise contains stove-pipe systems then the enterprise architecture would come up with a plan to migrate to a seamlessly integrated enterprise wide IT system, i.e. the integration architecture. The process dimension of the Enterprise Architecture would contain the roadmap to move from the AS-IS to the TO-BE scenario and also a Governance model for the architecture.

In the year 1987, John Zachman published a paper titled "A framework for information systems architecture". [6] But, it did not capture the industry's attention to the required extent for more than a decade. In an article published in 1999, Zachman enunciated why architecting did not catch industry's attention and also listed reasons why an architectural revolution was imminent for every enterprise that intended to be a player in the information age. [7] Zachman's analysis is now getting validated as a large number of players in the current scenario are adopting enterprise architecture.

Gartner, in September 2005, states "Many CIOs have established or inherited enterprise architecture programs with high hopes of improving IT by managing complexity, increasing IT agility and reducing cost and risk. These programs frequently flounder because many CIOs don't apply EA in their everyday work with the business, their staff, vendors and business partners." [10] The report identifies some drawbacks on enterprise architecture implementation by CIOs. However, the very fact that such a research was conducted illustrates how wide spread and established the titles of CIOs and the concept of enterprise architectures are in today's organizations.

\section{Enterprise Architecture Definition Framework}

Based on our experiences, we have formulated an Enterprise Architecture Definition Framework (EADF). The framework, like any framework, provides a skeletal structure that needs to be populated depending upon the context of the problem to which it is applied and needs to be adapted to the problem at hand. The key elements of an EADF are shown in Table 1.

The EADF provides guidance on how to develop various architectures constituting the enterprise architecture by way of drawing attention to the points that should be kept in mind while arriving at respective architectures which are shown as rows in the EADF matrix below. The various decisions related to business development and technology innovations need to be considered in a systematic manner within the framework of various architectures. Choices of methods and techniques have to be made in the context of the goals and objectives. [2] 


\section{Constituents of an Enterprise Architecture and relationship between the AS- IS \& TO-BE Architectures and concerns:}

As discussed in section 2, an Enterprise Architecture is made up of various architectures like Business, Information, Applications and Infrastructure Architectures. Further, each of the Architectures is related to various concerns.

AS-IS Architecture or AS-IS Artifact = function (Rationale, Process, Actors, Information, Location, Time)

However, one may not have much control in documenting AS-IS artifacts and Architectures. The customer might not be willing to spend more time and effort in documenting the existing scenarios. The Enterprise Architect would have to use discretion in identifying existing artifacts and architectures that would be useful in documenting the AS-IS scenarios and needs to negotiate with regard to the ones which are essential.

TO-BE Architecture or TO-BE Artifact = function (Rationale, Process, Actors, Information, Location, Time)

Enterprise Architecture needs a detailed sequencing plan to evolve the baseline architecture to the target architecture. The plan's major elements include program/business improvement IT projects and major infrastructure and technology upgrades. [14] Migration from AS-IS to TO-BE might use approaches like service-oriented architecture and building integration frameworks. The architecture governance identifies the roles and responsibilities of concerned stake holders. An escalation mechanism is planned and documented. Thus, both the model and process are captured.

\section{Strawman Table of Contents for EA documentation and governance:}

The EADF is supported by a Strawman version of Table of Contents (ToC) that would guide in documenting the important architectures of the EA. Points mentioned in the matrix have to be checked against when arriving at their respective architectures.

1. How to use this document

2. Introduction

3. Business Architecture

a. AS-IS Architecture

b. TO-BE Architecture

4. Information Architecture

a. AS-IS Architecture

b. TO-BE Architecture

5. Application Architecture 
a. AS-IS Architecture

b. TO-BE Architecture

6. Infrastructure Architecture

a. AS-IS Architecture

b. TO-BE Architecture

7. Security Architecture

a. AS-IS Architecture

b. TO-BE Architecture

8. Integration Architecture

9. Road Map to migrate from AS-IS to TO-BE

10. Architecture Governance

a. Architecture Governance Structure

b. Roles and Responsibilities of concerned stake holders

c. Escalation Mechanism

11. Appendix 
Architecture or

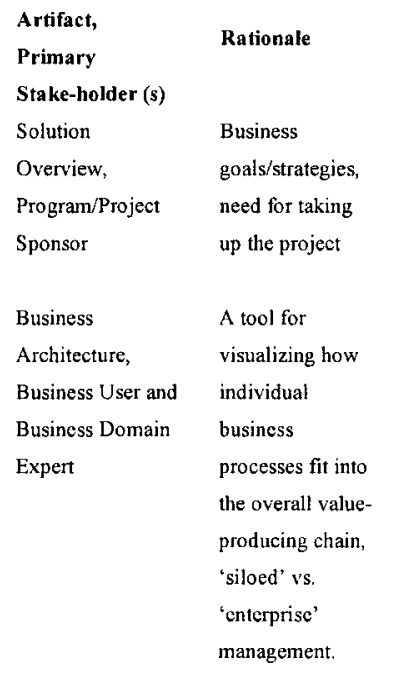

\begin{tabular}{|c|c|c|}
\hline $\begin{array}{l}\text { Information and } \\
\text { Data Architecture, } \\
\text { Business Domain } \\
\text { Expert and } \\
\text { Technology Expert }\end{array}$ & $\begin{array}{l}\text { Development of } \\
\text { strategies to } \\
\text { satisfy the needs } \\
\text { of the end users } \\
\text { (both naive and } \\
\text { advanced) and } \\
\text { the Senior } \\
\text { Management }\end{array}$ & $\begin{array}{l}\text { Identification of } \\
\text { online queries, } \\
\text { summary reports, } \\
\text { queries that give } \\
\text { intelligent reports } \\
\text { (e.g. use of data } \\
\text { warchouse) }\end{array}$ \\
\hline $\begin{array}{l}\text { Application } \\
\text { Architecture, } \\
\text { Business Domain } \\
\text { Expert and } \\
\text { Technology Expert }\end{array}$ & $\begin{array}{l}\text { Identification of } \\
\text { Applications that } \\
\text { need to be } \\
\text { replaced and } \\
\text { relationship } \\
\text { between new and } \\
\text { retained } \\
\text { applications }\end{array}$ & $\begin{array}{l}\text { How the } \\
\text { applications } \\
\text { intcract with } \\
\text { each other (e.g. } \\
\text { synchronous, } \\
\text { asynchronous) }\end{array}$ \\
\hline
\end{tabular}

$\begin{array}{lllll}\text { Processes the } & \text { Organizational } & \text { Things } & \text { Locations in } & \text { Events/cycles } \\ \text { business } & \text { units } & \text { important to } & \text { which the } & \text { important to } \\ \text { performs } & \text { important to } & \text { the business } & \text { business operates } & \text { business }\end{array}$

$\begin{array}{lllll}\text { Business Process } & \text { Work flow } & \text { Functional } & \text { Business } & \text { Master } \\ \text { Model } & \text { model (key } & \text { model, } & \text { logistics system } & \text { schedule } \\ \text { stakeholders } & \text { Process } & \text { (business } & \text { (including } \\ \text { in different } & \text { model, } & \text { locations and } & \text { business } \\ \text { organizational } & \text { Business } & \text { linkages - } & \text { events and } \\ \text { units (OUs) } & \text { entities, } & \text { detailed } & \text { cycles), } \\ \text { and their } & \text { Workflows. } & \text { infornation on } & \text { investigation } \\ \text { reporting } & \text { Key business } & \text { different OUs) } & \text { of suitability } \\ \text { relationships, } & \text { components } & & \text { of service } \\ & \text { with a work- } & \text { (functions) } & & \text { orientation }\end{array}$

flow

relationship)

\begin{tabular}{|c|c|c|c|}
\hline Who can & Functional & Location of users & Identification \\
\hline access the & Requirements & who would need & of Real time, \\
\hline data/informati & which lead to & the data and & Near Real \\
\hline on, which data & identification & information & Time and \\
\hline elements to & of data & & Batch \\
\hline protect and the & elements, & & Processing \\
\hline extent of & Data Model, & & requirements \\
\hline
\end{tabular}

protection? Information

Who should Names of Position of Identification

access which different applications in of

applications? applications layers and also communicatio

(both products their n styles (t.g.

and those geographical Messaging,

developed in- location service

house) oriented, etc.)

between

applications

\begin{tabular}{|c|c|c|c|c|c|c|}
\hline $\begin{array}{l}\text { Infrastructure } \\
\text { Architecture, } \\
\text { Technology Expert } \\
\text { and } \\
\text { Developer }\end{array}$ & $\begin{array}{l}\text { Identification of } \\
\text { required } \\
\text { hardware/ } \\
\text { software and } \\
\text { guidance on their } \\
\text { selection, } \\
\text { deployment and } \\
\text { maintenance }\end{array}$ & $\begin{array}{l}\text { Load, } \\
\text { performance, } \\
\text { scalability and } \\
\text { considerations } \\
\text { like trade-off due } \\
\text { to selection of } \\
\text { one } \\
\text { implementation } \\
\text { style over other } \\
\text { (e.g. use of } \\
\text { tomcat vs. WAS) }\end{array}$ & $\begin{array}{l}\text { User wise } \\
\text { Access } \\
\text { permissions } \\
\text { for varied } \\
\text { users, at a } \\
\text { high level }\end{array}$ & $\begin{array}{l}\text { Servers, } \\
\text { Clients, } \\
\text { Databases, } \\
\text { Networks, } \\
\text { Operating } \\
\text { Systems }\end{array}$ & $\begin{array}{l}\text { Connectivity } \\
\text { issues for the } \\
\text { chosen } \\
\text { environment } \\
\text { (e.g. bandwidth } \\
\text { considerations) }\end{array}$ & $\begin{array}{l}\text { Support for } \\
\text { style and type } \\
\text { analyzed } \\
\text { above (e.g. } \\
\text { Message } \\
\text { Oriented } \\
\text { Middleware } \\
\text { like MQ } \\
\text { Series, } \\
\text { Enterprise } \\
\text { Service Bus, } \\
\text { etc.) }\end{array}$ \\
\hline
\end{tabular}




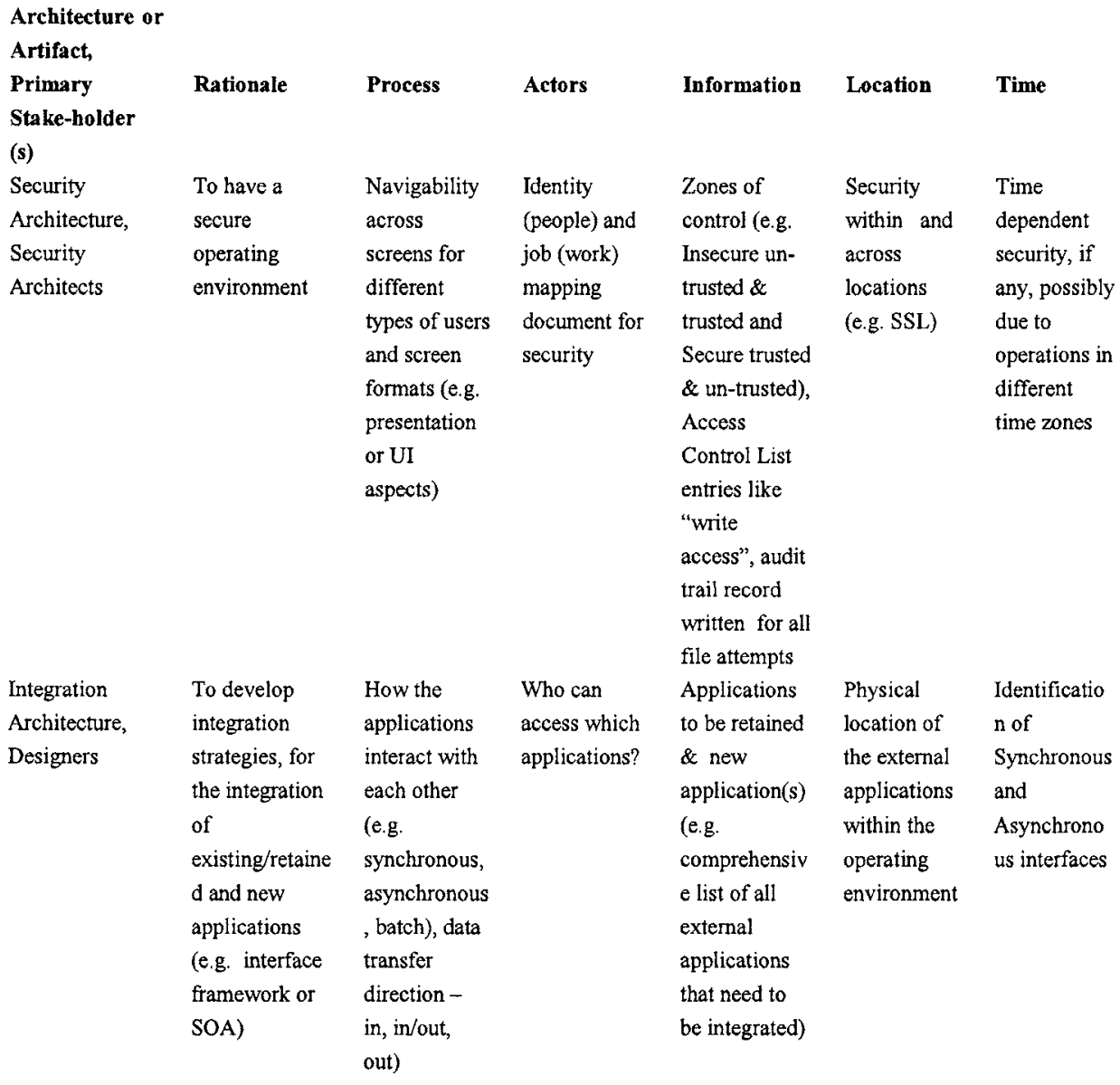

Table 1 Enterprise Architecture Definition Framework

\section{Case Studies}

There is no one right way or a single industry standard for defining architecture, so agreement within an enterprise is more important than theoretical perfection. [3] Based on customer engagements we have arrived at an EADF, as discussed in section 3 above. The case studies deal with the integration of information systems. 
Many existing Information Systems (IS) supporting an organization's business processes, are considered "automation islands", since they cannot communicate easily with systems inside the organization and even less outside it, with external systems of clients and suppliers. In order to provide a complete, efficient and reliable support, the IS must be integrated. IS integration means to unify independent IS, with the purpose of providing shared information and give a valid support to the whole organizational process. [8]

\subsection{Enterprise Architecting for a large Bank}

The customer is a large bank that has grown rapidly through mergers and acquisitions. This inorganic growth has led to the bank having heterogeneous applications for the same functionality. This led to a scenario of stove pipe applications or "automation islands". The bank has decided to centralize the functionality and has identified a third party vendor who would provide an off the shelf solution.

In order to see how the entire business processes and the information/data would get integrated Enterprise Architecture was defined. Our organization had been engaged as an IT service provider to finalize the EA. In this context we used the EADF to document the EA, provide a road map and architecture governance. Apart from the offshore study an onsite visit was undertaken to arrive at the EA. Among others, the team included a Domain Architect and an Enterprise Architect.

The AS-IS and TO-BE architectures of the business, information, application, infrastructure and security were documented. The EADF was used to guide in the definition of the architectures. It was ensured that the concerns mentioned in the columns of the EADF, shown in Table 1, were part of the architecture/artifacts for each of the architectures/artifacts. Thus, for a given row, the architecture/artifacts addressed all the mentioned concerns. Further, it was ensured that there is traceability between the various architectures for a given concern i.e. as we go down a given column of the EADF, shown in Table 1, the architectures/artifacts are generally at a lower level of abstraction but there is continuity of thought process for a given concern. The standards and guidelines related to the different architectures were included in the appendix. A road map to migrate from the ASIS to TO-BE state, and architecture governance framework were recommended. Roles and responsibilities of concerned stake holders along with an escalation mechanism, in case of deviations, were documented.

The customer had taken a decision to take the non-SOA path, as its policy is to be an early follower than to be a leader in the adoption of new or emerging technologies. Hence, a solution that involves the creation of an Integration Framework was recommended and is as shown in Fig. 1. 


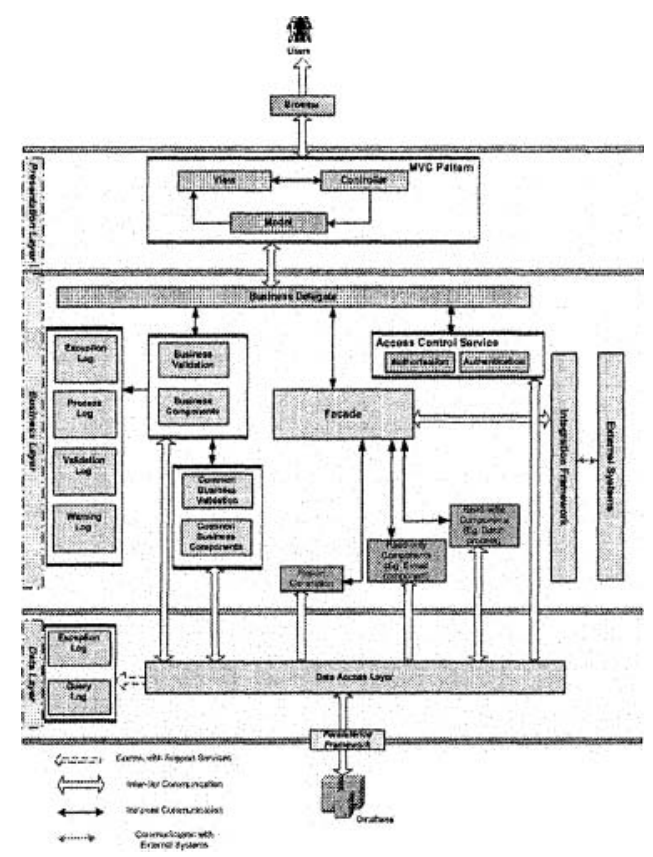

Fig. 1. A J2EE based application that would integrate with other applications through the Integration Framework

The design of the Integration Framework adopted an approach of integrating various applications in a plug and play manner.

\subsection{Enterprise Architecting for a Financial Services customer}

The customer is a large financial corporation. Over a period of time, it has developed and acquired varied systems that cater to the required functionality. The existence of varied legacy systems had led to a situation where it was becoming difficult to maintain them. The customer wanted a migration of their applications to newer platforms. Proactively, it wanted to have an EA that would make the systems maintainable and enable it to integrate any new technologies/applications that the customer would develop or acquire in future. An approach similar to the one discussed in the earlier case study was used to arrive at Enterprise Architecture.

As the customer was willing to adopt SOA, a solution based on SOA was proposed. Strawman architecture for enterprise wide SOA was recommended. 
Subsequently, a detailed study of the IT systems was undertaken to arrive at the final recommendation.

A central aspect of Service Oriented Architectures is the loose coupling between applications (services) that are achieved when services publish their functional and non-functional behavioral characteristics in a standardized, machine-readable format as indicated in [9]. In this section, discussion is not restricted to a particular technology. A generic view of a service is considered.

The Strawman Architecture presented in this section could serve as a starting point for developing a SOA based solution for an Enterprise. Fig. 2 represents a Strawman for Enterprise-Wide SOA recommended to the customer.

It can be seen from the figure that the enterprise has several applications that need to talk to each other. A key feature of the architecture is the use of Enterprise Service Bus (ESB) that enables a smooth communication between the applications. ESB is often described as a product, especially in the marketing literature of various vendors. But, in a strict sense, ESB is an architectural style. The Strawman architecture for Enterprise-Wide SOA has the ESB as the heart of communication between applications. $[1,11,12]$

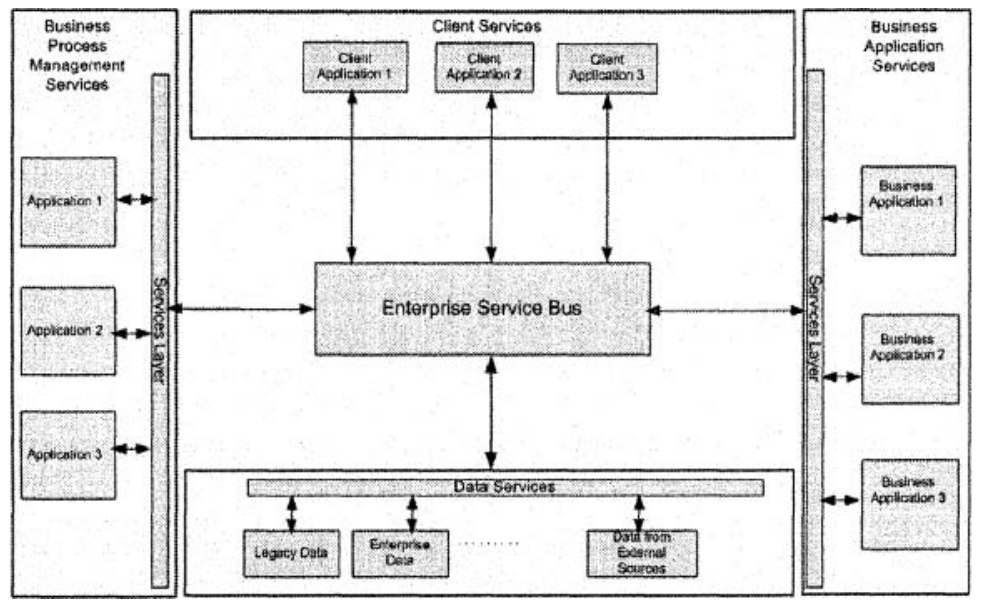

Fig. 2. Strawman for Enterprise-Wide SOA

\section{Conclusions}

This paper has captured experiences in providing EA based solutions for enterprise applications. The Enterprise Architecture Definition Framework 
enables an Enterprise or an IT Service Provider to quickly arrive at the required Enterprise Architecture definition. The strawman table of contents helps in documenting the enterprise architecture, a road map to migrate from AS-IS to TOBE state and an architecture governance model. The SOA and non-SOA based approaches for integration that have been discussed as part of case studies provide approaches for enterprise and solution architecting of the enterprise's applications. The framework, tools and techniques discussed in the paper would reduce the time and resources required for enterprise architecting by IT service providers.

\section{References}

1. S. Kambhampaty and S. Chandra, Service Oriented Architecture for Enterprise Applications presented at WSEAS conference held on $15^{\text {th }}$ February, 2006 at Madrid Spain. Published in the WSEAS Proceedings and in the issue of WSEAS Transactions on Business and Economics.

2. J. Schekkerman, How to survive in the jungle of Enterprise Architecture Frameworks: Creating or choosing an Enterprise Architecture Framework, Trafford 2003

3. R. Heffner, The Pillars of Enterprise Architecture Terminology, Giga Information Group, November 11, 2002.

4. Mike Rosen, Implementing Enterprise Architecture with MDA, www.omg.org.

5. P.R. Reed, Jr., Reference architecture: The best of best practices, Published on IBM Website, January 302004.

6. J.A. Zachman, A framework for information systems architecture, IBM Systems Journal, 26(3), (1987).

7. J.A. Zachman, Enterprise Architecture: The Past and the Future, Article published in DM Review Magazine December 1999.

8. F. Losavio, D. Ortega, and M. Pérez, Comparison of EAI Frameworks, Journal of Object Technology 4(4), 93-114 (2005). http://www.jot.fm/issues/issue_2005_05/article1.

9. N.K. Mukhi, R. Konuru, and F. Curbera, Cooperative Middleware Specialization for Service Oriented Architectures, International World Wide Web Conference archive Proceedings of the 13th international World Wide Web conference on Alternate track papers \& posters table of contents New York, NY, USA SESSION: Semantics and discovery table of contents, (2004) pp. $206-215$.

10. C. Tucker and D. Aron, Executive Summary of the Research Report on Applying Enterprise Architecture, research conducted by Gartner in September, 2005.

11. R. Robinson, Understanding Enterprise Service Bus scenarios and solutions in ServiceOriented Architecture, Parts 1 to 8 , www-128.ibm.com/developerworks/xml/library/.

12. M. Endrei, J. Ang, A. Arsanjani, S. Chua, P. Comte, P. Krogdahl, M. Luo, and T. Newling, Patterns: Service- Oriented Architecture and Web Service, IBM Red Book, www.ibm.com/redbooks.

13. J. Evdemon, The Four Tenets of Service Orientation, article from bpminstitute.org at http://www.bpminstitute.org/articles/article/article/the-four-tenets-of-service-

orientation.html 
14. J. Zhong, From stove-piped projects to unified enterprise architecture, Java World, March 2003. 